\title{
Utilização de Colina e Betaína na Nutrição da Tilápia do Nilo (Oreochromis niloticus)
}

\author{
Ivan Vieira \\ Engenheiro Agrônomo
}

Orientador: Prof Dr. José Eurico Possebon Cyrino

Dissertaçāo apresentada à Escola Superior de Agricultura "Luiz de Queiroz", Universidade de São Paulo, para obtençāo do título de Mestre em Agronomia, Área de Concentraçāo: Ciência Animal e Pastagens

Piracicaba

Estado de São Paulo - Brasil

Julho - 2000 


\section{Página 17}

Correções em todas as colunas da Tabela 3.

Tabela 3. Resultados de desempenho e concentração corporal e hepática de lipídios obtidos no Experimento I.

\begin{tabular}{lcccccc}
\hline $\begin{array}{c}\text { Suplementação } \\
\text { de colina/kg de } \\
\text { alimento }\end{array}$ & $\begin{array}{c}\text { Peso inicial } \\
\text { do lote }\end{array}$ & $\begin{array}{c}\text { Ganho de } \\
\text { peso }\end{array}$ & $\begin{array}{c}\text { Conversão } \\
\text { alimentar }\end{array}$ & $\begin{array}{c}\text { Concentração } \\
\text { de lipídios no } \\
\text { tecido corporal }\end{array}$ & $\begin{array}{c}\text { Concentração } \\
\text { de lipídios no } \\
\text { fígado }\end{array}$ & Sobrevivência \\
\hline$(\mathrm{mg})$ & $(\mathrm{g})$ & $(\mathrm{g})$ & $(\mathrm{g} / \mathrm{g})$ & $(\%)$ & $(\%)$ & $(\%)$ \\
0 & $50,99 \pm 1,24$ & $97,43 \pm 5,23$ & $1,37 \pm 0,11$ & $20,92 \pm 1,43$ & $5,74 \pm 0,92$ & $100 \pm 0,00$ \\
375 & $50,18 \pm 0,23$ & $108,12 \pm 3,75$ & $1,21 \pm 0,05$ & $20,72 \pm 1,43$ & $5,70 \pm 0,76$ & $100 \pm 0,00$ \\
750 & $52,09 \pm 2,52$ & $104,86 \pm 3,40$ & $1,24 \pm 0,05$ & $21,56 \pm 1,54$ & $4,82 \pm 0,84$ & $100 \pm 0,00$ \\
1125 & $51,31 \pm 1,41$ & $106,63 \pm 8,97$ & $1,29 \pm 0,13$ & $20,94 \pm 0,93$ & $6,84 \pm 0,91$ & $98 \pm 4,47$ \\
1500 & $50,04 \pm 0,38$ & $105,32 \pm 3,93$ & $1,26 \pm 0,04$ & $21,54 \pm 0,47$ & $5,00 \pm 2,65$ & $100 \pm 0,00$ \\
1875 & $50,60 \pm 0,54$ & $105,11 \pm 4,21$ & $1,22 \pm 0,03$ & $21,21 \pm 1,82$ & $6,16 \pm 1,71$ & $100 \pm 0,00$ \\
\hline
\end{tabular}

Página 20

Correções em todas as colunas da Tabela 4.

Tabela 4. Resultados de desempenho e concentração corporal e hepática de lipídios obtidos no Experimento II.

\begin{tabular}{lcccccc}
\hline $\begin{array}{c}\text { Suplementação } \\
\text { kg de alimento }\end{array}$ & $\begin{array}{c}\text { Peso inicial } \\
\text { do lote }\end{array}$ & $\begin{array}{c}\text { Ganho de } \\
\text { pesio }\end{array}$ & $\begin{array}{c}\text { Conversão } \\
\text { alimentar }\end{array}$ & $\begin{array}{c}\text { Concentração } \\
\text { de lipídios no } \\
\text { tecido corporal }\end{array}$ & $\begin{array}{c}\text { Concentração } \\
\text { de lipídios no } \\
\text { fígado }\end{array}$ & Sobrevivência \\
\hline$(\mathrm{mg})$ & $(\mathrm{g})$ & $(\mathrm{g})$ & $(\mathrm{g} / \mathrm{g})$ & $(\%)$ & $(\%)$ & $(\%)$ \\
0 & $21,90 \pm 0,66$ & $87,22 \pm 4,5$ & $1,64 \pm 0,11$ & $27,90 \pm 2,45$ & $10,66 \pm 2,09$ & $98 \pm 4,47$ \\
colina, 1250 & $21,49 \pm 0,66$ & $89,09 \pm 8,19$ & $1,57 \pm 0,15$ & $28,73 \pm 2,08$ & $11,58 \pm 3,57$ & $94 \pm 9,94$ \\
colina, 2500 & $21,32 \pm 0,86$ & $93,03 \pm 6,35$ & $1,52 \pm 0,10$ & $28,93 \pm 0,93$ & $9,70 \pm 1,47$ & $100 \pm 0,00$ \\
betaina, 1000 & $21,44 \pm 0,66$ & $81,96 \pm 5,93$ & $1,61 \pm 0,14$ & $27,17 \pm 1,95$ & $8,45 \pm 0,57$ & $96 \pm 5,48$ \\
betaína, 2000 & $21,88 \pm 0,87$ & $87,72 \pm 12,11$ & $1,60 \pm 0,22$ & $27,26 \pm 1,36$ & $12,01 \pm 2,66$ & $94 \pm 5,48$ \\
betaína, 3000 & $21,39 \pm 0,83$ & $12,51 \pm 2,83$ & $9,30+2,05$ & $28,68 \pm 1,78$ & $13,92 \pm 2,32$ & $94 \pm 8,94$ \\
\hline \hline
\end{tabular}


Dados Internacionais de Catalogação na Publicação (CIP) DIVISĀO DE BIBLIOTECA E DOCUMENTAÇĀO - Campus "Luiz de OueirOz"/USP

\author{
Vieira, Ivan \\ Utilização de colina e betaina na nutrição da tilápia do Nilo (Oreachromis niloticus) \\ / Ivan Vieira. - - Piracicaba, 2000. \\ $29 \mathrm{p}$. \\ Dissertaçāo (mestrado) - - Escola Superior de Agricultura Luiz de Queiroz, 2000. \\ Bibliografia. \\ 1. Betaina 2. Colina 3. Nutrição animal 4. Tilápia-do-Nilo I.Título
}

CDD 639.31

Permifida a copia total ou parcial deste documento desde que citada a fonte -0 autro 
À minha mãe, Odette Cretella Vieira,

pelo apoio e dedicação incansáveis,

meu pai, Pedro Jarbas Vieira (in memorian)

que onde estiver, sei que sempre olha por mim,

dedico. 


\section{AGRADECIMENTOS}

Ao final deste trabalho, quero agradecer aqueles que, direta ou indiretamente, contribuíram para a sua realização:

Ao Prof. Dr. José Eurico Possebon Cyrino, pela orientação, ensinamentos e principalmente apoio e amizade;

A Prof. Dr. Maria Cristina Stolf Nogueira, do Departamento de Ciências Exatas, pelo auxílio e orientação;

Ao Conselho Nacional de Desenvolvimento Científico e Tecnológico CNPq, pela bolsa de estudos concedida;

Aos Professores dos Departamento de Produção Animal pela oportunidade de aprendizado.

À Granja Mizumoto, na pessoa do Sr. Gilson Taigi Nishitani, à Betch, na pessoa do Sr. Roberto Betancourt e a Supremais, na pessoa do Sr. Roberto Butullo, pelo fornecimento do material para condução do experimento;

Ao Prof. Dr. Luiz Edivaldo Pezzato, da UNESP-Botucatu, pela cessão das instalaçōes de seu laboratório e auxílio na confecção das dietas experimentais;

Aos colegas e estagiários do setor de piscicultura, Leonardo "Banana" Tachibana e Rafael "Musquito" Campagnol, pelo auxílio na condução dos trabalhos;

Aos colegas de turma Ana Maria B. M. "Linguiça" Sampaio, Mônica Accaui Marcondes de Moura e Gláucio Nogueira “Toyota” Toyama;

Aos meus amigos Marco Antônio Alvares “Moxo" Balsalobre e Ricardo Franklin "Koliforme" de Mello, pelo apoio e companheirismo;

A Juliana Amaral de Mendonça, a pessoa mais importante de minha vida, pela paciência, dedicação, compreensão e incentivo. 


\section{SUMÁRIO}

Página

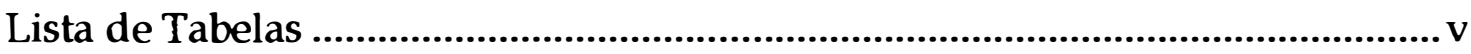

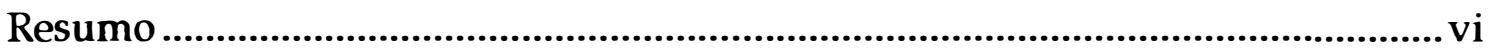

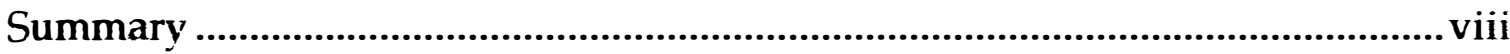

1. Introdução ………............................................................................................................ 1

2. Revisão de Literatura

2.1. Espécie em estudo ................................................................................. 3

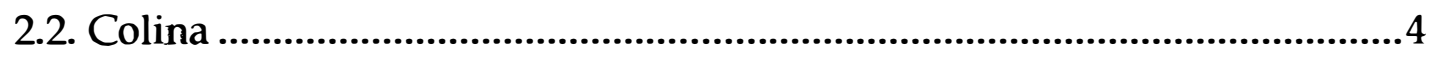

2.3. Betaína .........................................................................................................

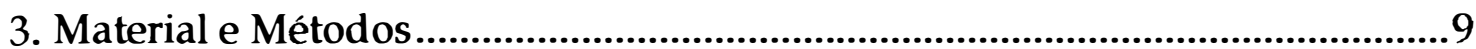

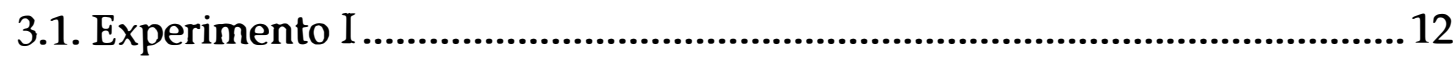

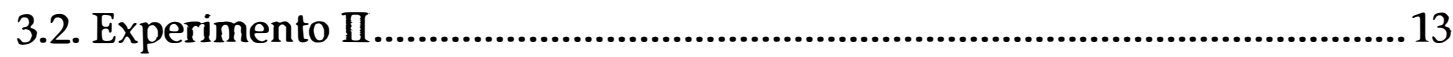

3.3. Procedimentos analíticos ............................................................................ 14

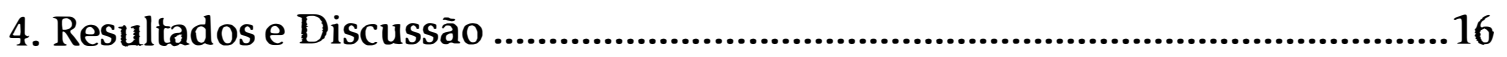

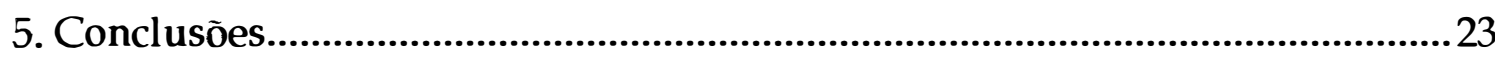

Referências Bibliográficas ...................................................................................24 


\section{LISTA DE TABELAS}

Página

1. Composição centesimal da ração purificadada................................................11

2. Composição bromatológica das raçōes experimentais ...................................12

3. Resultados obtidos no experimento $I$, com a utilização de diferentes doses de cloreto de colina

4. Resultados obtidos no experimento II, com a utilização de diferentes doses de cloreto de colina $(C)$, comparadas à betaína (B) 


\title{
Utilização de Colina e Betaína na Nutrição da Tilápia do Nilo (Oreochromis niloticus)
}

\author{
Autor : Ivan Vieira \\ Orientador. Prof. Dr. José Eurico P. Cyrino
}

\section{RESUMO}

Com o objetivo de determinar a exigência nutricional de colina para a tilápia do Nilo (Oreochromis niloticus), e a possibilidade de se utilizar a betaína em substituição à colina, rações purificadas com a inclusão de 0; 375 mg; $750 \mathrm{mg}$; $1.125 \mathrm{mg} ; 1.500 \mathrm{mg}$ ou $1.875 \mathrm{mg}$ de cloreto de colina por $\mathrm{kg}$ de ração, foram administradas ad libitum, duas vezes ao dia, sete dias por semana, por seis semanas (42 dias), a grupos de 10 tilápias do Nilo com peso médio de 5,09 $\pm 0,14$ $\mathrm{g}$, estocados em 30 gaiolas de policloreto de vinila átoxico de abertura de malha $5 \mathrm{~mm}$ e volume unitário de $60 \mathrm{~L}$, alojadas em caixas de polipropileno de $1000 \mathrm{~L}$, em ambiente com condições controladas de temperatura e luminosidade. Foi utilizado um delineamento experimental em blocos incompletos totalmente ao acaso, com 3 parcelas em cada bloco, com 5 repetições por tratamento. Não foram observadas diferenças significativas para a quantidade de lipídeos no fígado, no tecido corporal e sobrevivência, mas foram observadas diferenças significativas para ganho de peso e conversão alimentar, sendo todos os tratamentos superiores ao controle. Num segundo experimento, com duração de 52 dias, foram avaliados os efeitos da suplementação dietética de colina em doses mais elevadas e da substituição da colina por betaína nas dietas. As rações foram suplementadas com $1.250 \mathrm{mg}$ ou $2.500 \mathrm{mg}$ de colina por $\mathrm{kg}$ de alimento; $1.000 \mathrm{mg} ; 2.000 \mathrm{mg}$ ou $3.000 \mathrm{mg}$ de betaína $\mathrm{kg}$ de alimento, mantendo-se um tratamento controle. Não foram observadas diferenças significativas para sobrevivência e acúmulo de lipídeos, tanto no fígado como no tecido corporal, 
entre os tratamentos. Em relação à conversão alimentar e ganho de peso, os tratamentos com suplementação de colina foram superiores ao tratamento controle e aos tratamentos com suplementação de betaína, mas não diferiram entre si. Com base nos resultados, conclui-se que níveis de suplementação superiores a $375 \mathrm{mg}$ de cloreto de colina por $\mathrm{kg}$ de alimento são suficientes para atender as exigências da tilápia do Nilo, melhorando a conversão alimentar e o ganho de peso da espécie, e que a betaína nào substitui efetivamente a colina em rações para tilápia do Nilo. 


\section{UTILIZATION OF CHOLINE AND BETAINE FOR NILE}

TILAPIA (Oreochromis niloticus) NUTRITION

Author: Ivan Vieira

Adviser: Prof. Dr. José Eurico P. Cyrino

\section{SUMMARY}

The study investigates the utilization of choline and betaine as feed supplement for the Nile tilapia Oreochromis niloticus. Groups of 10 fingerlings $(5.09 \pm 0.14 \mathrm{~g})$ were stocked in 30 PVC cages $(60 \mathrm{~L})$, kept in controlled environmental conditions inside 1000-L plastic pools, and fed to satiation, twice a day for 42 days, purified diets supplemented with $0 \mathrm{mg}, 375 \mathrm{mg}, 750 \mathrm{mg}, 1125$ $\mathrm{mg} 1500 \mathrm{mg}$ or $1875 \mathrm{mg}$ of choline chloride per $\mathrm{kg}$ of feed. Trial was set up in an incomplete, totally randomized block design $(n=5)$. There were no significant differences among treatments for total body and liver lipids contents and survival rate; there were significant differences for weight gain and food conversion ratio between the control and all the other treatments, but not between the different supplementation levels. A second trial (52 days), evaluated the effects of higher dosages of choline - 1250 or $2500 \mathrm{mg}$ per $\mathrm{kg}$ of feed, and the substitution of choline by betaine in the diets $-1000 \mathrm{mg}, 2000 \mathrm{mg}$ or $3000 \mathrm{mg}$ of betaine per $\mathrm{kg}$ of feed and a control diet. Once again, there were no significant differences among treatments for total body and liver lipids contents and survival rate. Feed conversion ratios and weight gain of fish fed betaine-supplemented and control diets were significantly worse than fish fed choline-supplemented diets. There were no differences on performance of fish fed the choline-supplemented diets. Based on results, it can be concluded that supplementation of $375 \mathrm{mg}$ of choline per $\mathrm{kg}$ of feed meet nutritional 
requirements of Nile tilapia, and betaine do not substitute choline effectively in diets for the species. 


\section{INTRODUÇÃO}

A aquicultura apresentou um crescimento constante na América Latina e Caribe no período de 1984-95, com uma taxa de crescimento anual de $12,8 \%$. A produção total na região, em 1995, respondeu por $1,8 \%$ da produção mundial, com 499.000 toneladas métricas e gerando um volume de negócios de US\$1,87 bilhão, correspondente a $4,4 \%$ do valor mundial gerado pela atividade. Deste valor, 23\% foram gerados pela aquicultura (Martinez e Pedini, 2000).

No mesmo período, a produção mundial da aquicultura aumentou de 6,7 para 20,9 milhões de toneladas métricas. Isto significa que a produção mundial da aquicultura responde pelo equivalente a 13,7 milhōes de toneladas de carne para consumo humano (após processamento), o que corresponde a $6,2 \%$ da produção mundial total de 222,1 milhōes de toneladas, ocupando a quarta posição, abaixo das carnes suína $(37,6 \%)$, bovina $(24,0 \%)$ e de frango $(20,9 \%)$, e acima das carnes de carneiro $(3,2 \%)$ e de outras carnes, que juntas representam $8,1 \%$ do total (Tacon, 2000).

A demanda por pescado vem crescendo substancialmente. Se for levado em consideração que os estoques naturais, tanto de água doce como de água salgada, encontram-se em fase de esgotamento, e há necessidade de aumento na produção de alimentos em nosso país, a piscicultura deve assumir um papel cada vez mais importante no sistema agro-industrial no Brasil. Levando-se em conta ainda que o país apresenta ainda baixo consumo médio anual per capita de pescado $(4,9 \mathrm{~kg})$, em comparação com valores referentes a países como Japão $(68 \mathrm{~kg})$, Portugal $(36 \mathrm{~kg})$ e Estados Unidos $(7,5 \mathrm{~kg})$ 
(FAO,1994), a aquicultura brasileira assume importância estratégica no contexto da produção de alimentos para consumo humano.

Esses fatores tornam a piscicultura uma atividade promissora dentro do sistema agro-industrial nacional. $O$ desenvolvimento da aquicultura vai possibilitar ainda aos produtores rurais a diversificação de suas atividades e incremento na receita da propriedade. Finalmente, deve-se considerar as alternativas de lazer e turismo rural, atividade em que estão inseridos os estabelecimentos de pesca esportiva, segmento que tem experimentado os maiores avanços na história recente da aquicultura brasileira, mostrando-se como alternativa interessante para a comercialização do pescado produzido em confinamento (Martin et al., 1995; Scorvo Filho \& Ayrosa, 1996; Scorvo Filho et al., 1998).

Apesar do grande número de espécies exploradas comercialmente, a formulação de rações para piscicultura é geralmente feita com base em tabelas de exigências nutricionais determinadas para aproximadamente 10 espécies apenas. As exigências das demais espécies são determinadas por analogia, levando em consideração semelhanças quanto à hábito alimentar, habitat (água salgada ou doce), faixa climática de ocorrência da espécies, etc. (Wilson, 1995).

Considerando a importância estratégica da área para a agro-indústria brasileira, a realização de trabalhos relativos à determinação de exigências nutricionais de espécies com cadeia agro-industrial bem definida é uma necessidade imediata. Justifica-se então a realização deste trabalho com a tilápia do Nilo, espécie reconhecidamente importante para a aquicultura trasileira em função do grande potencial de produção que apresenta. 


\section{REVISÃO DE LITERATURA}

\section{Espécie em estudo}

A tilápia do Nilo (Oreochromis niloticus L.) foi introduzida no Brasil em Pentecoste no Ceará através do DNOCS. É um peixe de hábito alimentar fitoplanctófago, bastante rústico e relativamente precoce. Seu peso comercial é de 400 a 500 gramas o que pode ser alcançado com 6 a 8 meses em criação (Castagnolli, 1992).

A espécie O. niloticus apresenta escamas grandes, pouco brilhantes, listras verticais contínuas na nadadeira caudal, coloraçào esbranquiçada no ventre e prateada no dorso. É uma espécie típica de ambiente tropical; adapta-se melhor a temperaturas entre 18 a $28^{\circ} \mathrm{C}$ e a faixa de $\mathrm{pH}$ ideal para a espécie está entre 7 e 8 . A espécie tem tolerância a variaçōes de salinidade e a baixos níveis de oxigênio dissolvido, suportando até 2 a $3 \mathrm{mg} / \mathrm{L}$ de oxigênio dissolvido na água. As fêmeas incubam os ovos na boca por sete a oito dias, liberando as póslarvas apenas após a absorção do saco vitelínico (Lund \& Figueira, 1989).

A produção mundial de tilápias cresceu de 515.000 toneladas métricas em 1984 para 1,16 milhōes em 1995, sendo que a aquicultura contribuiu com $38 \%$ e $57 \%$, respectivamente, deste total. A tilápia do Nilo responde por $72 \%$ do total produzido pela aquicultura, ou seja 474.000 toneladas métricas (Rana, 2000). As tilápias do Nilo, moçambicana e aurea pertencem todas a um mesmo grupo de espécie indistintamente chamadas de tilápias, grupo este que representou 99,5\% do total de cichlideos produzidos mundialmente em 1995 (Rana, 2000). 


\subsection{Colina}

A colina foi isolada primeiramente da bile de porco por Streker em 1849. É uma substância biologicamente ativa, com peso molecular de 139,6. Embora seja empiricamente classificada como vitamina hidrossolúvel do complexo $\mathrm{B}$, não corresponde à definição de vitamina sob qualquer condição, uma vez que pode ser sintetizada por várias espécies, mas geralmente em quantidades insuficientes ou não rapidamente disponível para atender às exigências do animal. Geralmente é exigida em grandes quantidades nas dietas. Assume maior importância como fator de manutenção da estrutura celular, daí sua classificação de quase-vitamina por alguns autores (McDowell, 1989; Combs, 1992; National Research Council - NRC, 1993).

A colina é também denominada fator lipotrófico e pode ser encontrada em três formas, tanto em células animais como vegetais: colina livre; acetilcolina; ou lecitina em fosfolipídeos. As funções básicas da colina no metabolismo animal são: como componente essencial da acetilcolina, um neurotransmissor do qual a colina é precursor; como fosfatidilcolina, que é um elemento estrutural da membrana celular, transmissão do impulso nervoso e também na utilização de lipídeos; como precursor da betaína, um doador de grupos metil para as reações de metilação e formação da metionina.

A forma cristalina de colina pura é incolor, viscosa e altamente higroscópica. A colina é solúvel em água, álcool e formaldeído e não possui ponto de ebulição e fusão determinados. A forma sintética cloreto de colina, que possui $86,8 \%$ de colina, é normalmente utilizada na indústria da alimentação animal.

A biodisponibilidade da colina presente nos farelos de soja, canola ou amendoim para frangos é de 83,24 e $76 \%$, respectivamente. Conforme 
observações de Emmert \& Baker (1997), esta disponibilidade não é afetada pelo processamento ao qual esses farelos são submetidos. Aburto et al. (1998) observaram que o processamento não afeta a quantidade de colina presente no farelo de soja e Menten et al. (1997) determinaram que biodisponibilidade da colina presente no farelo de soja para frangos é de cerca de $100 \%$.

Segundo Ramirez \& Cromwell( 1997) a adição de $330 \mathrm{mg}$ de colina por kg de uma ração à base de sorgo e farelo de soja com $10,5 \%$ de proteína bruta não apresenta quaisquer efeitos benéficos para suínos em crescimento.

Ryu et al (1995) demonstraram que aves de postura alimentadas com rações à base de milho e farelo de soja, contendo $23 \%$ de P.B. e $750 \mathrm{mg} / \mathrm{kg}$ de colina presente nos ingredientes, não apresentaram sinais de deficiência do nutriente. Neste caso, a adição de $500 \mathrm{mg}$ de colina para cada $\mathrm{kg}$ de ração, totalizando $1250 \mathrm{mg} / \mathrm{kg}$, diminui a exigência total de ácido fólico de $1,3 \mathrm{mg} / \mathrm{kg}$ (adição de $0,75 \mathrm{mg} / \mathrm{kg}$ ração) para $1,2 \mathrm{mg} / \mathrm{kg}$ (adição de $0,5 \mathrm{mg} / \mathrm{kg}$ ). Foi observado também por Tsiagbe et al. (1992) que a colina também pode substituir e ser substituída parcialmente pela metionina nas raçōes para aves de postura, sem prejuízo da produção e da qualidade dos ovos.

Em um trabalho de revisão sobre nutrição de larvas de camarão, Teshima et al. (1993) encontraram não só resultados bastante diversos em relação às exigências de colina por várias espécies do crustáceo, variando de $0,06 \%$ até $0,3 \%$, como também de dados que permitiam discutir a necessidade ou não da inclusão de colina em raçôes para camarōes. As exigências de colina em peixes variam muito em funçâo da espécie, da fase de desenvolvimento, e também em relação aos parâmetros utilizados para avaliação, como ganho de peso ou concentração de lipídeos no fígado e tecido corporal. Woodward (1994) reporta que as exigências nutricionais de colina para salmonídeos podem variar de 830 a $4050 \mathrm{mg} / \mathrm{kg}$.

Tentando determinar um suplemento com potencial para aumentar a disponibilidade dos minerais de uma farinha de peixe utilizada na composição 
de ração para peixes, Sugiura et al (1998) demonstraram que a administração de uma mistura de inositol e colina para truta arco-íris, em comparação com ácido cítrico, citrato de sódio, cloreto de potássio, cloreto de sódio, bicarbonato de sódio, dihidrocloreto de histamina, sal disódico EDTA, uma mistura de aminoácidos, ácido ascórbico e colecalciferol, não apresentou efeito positivo sobre a disponibilidade dos minerais.

Analisando o crescimento, a eficiência alimentar, a concentração total de lipídeos no plasma e fígado, as concentrações plasmáticas de triglicerídeos, colesterol e fosfatidil colina do "red drum" (Sciaenops ocellatus), alimentados com raçōes contendo $250 \mathrm{mg}, 500 \mathrm{mg}$, $750 \mathrm{mg}$, 1000mg e $1500 \mathrm{mg}$ de colina, ou uma ração padrão sem inclusão do nutriente, Craig \& Gatlin (1996) determinaram que as exigências em colina da espécie variam entre $330-676 \mathrm{mg} / \mathrm{kg}$.

Utilizando-se de duas fontes de colina, bitrato de colina e cloreto de colina, nas quantidades de $0,250 \mathrm{mg}, 500 \mathrm{mg}, 1.000 \mathrm{mg}, 2.000 \mathrm{mg}, 4.000 \mathrm{mg}$, $6.000 \mathrm{mg}$ e $8.000 \mathrm{mg}$ na alimentação de um híbrido do "striped bass" (Morone saxatilis X M. chrysops), Griffin et al. (1994) demonstraram que a inclusão de 500 mg de cloreto de colina por $\mathrm{kg}$ de ração condicionam as melhores respostas em termos de ganho de peso e concentração de lipídeos no fígado da espécie. 


\subsection{Betaína}

A betaína é um composto aromático encontrado naturalmente nas células animais. O produto comercial, com $96 \%$ de betaína, possui forma de cristais branco-amarelados, tem peso molecular de 117,5, é altamente higroscópico, é estável em temperaturas de até $200{ }^{\circ} \mathrm{C}$, e pode ser obtido do melaço de beterraba por separação cromatográfica.

A betaína atua na regulação do equilíbrio osmótico e é a única fonte doadora de grupos metil prontamente ativa. Outros doadores, como a colina e a metionina, precisam passar por transformaçōes: a colina precisa ser convertida em betaína na mitocondria celular e a metionina precisa ser ativada através da síntese de S-adenosil-metionina (SAM) (Betancourt, 1999).

Acrescentando $0,125 \%$ de betaína a uma ração formulada à base de milho e farelo de soja para suínos, com suplementação adequada de vitaminas, minerais e aminoácidos, Matthews et al. (1998) não observaram efeitos consistentes, e relacionaram os possíveis efeitos da betaína aos níveis energéticos e protéicos da ração. De forma semelhante, Schutte et al. (1997), alimentaram 2.400 frangos de corte, durante 38 dias, com duas raçôes suplementadas com colina e contendo uma combinação de três níveis de DL-metionina $(0,0,05 \mathrm{e}$ $0,10 \%$ ) e dois níveis de betaína ( 0 e $0,04 \%$ ), chegaram à conclusão que a betaína não pode substituir esse aminoácido essencial.

O papel de doador de grupos metil e palatabilizante desempenhado pela betaína foi estudado por Penãflorida \& Virtanen (1996). Trabalhando com juvenis de Penaeus monodon, alimentados com rações contendo grande quantidade de proteína de origem vegetal, com níveis de inclusão de 0;0,5\%; $1,0 \% ; 1,5 \%$ e $2,0 \%$ do produto comercial FinnStim, que possui além da betaína, alanina, isoleucina, leucina, valina e glicina, os autores concluíram que o produto é uma alternativa competitiva para balancear raçōes com grandes quantidades de ingredientes vegetais, as quais poderiam apresentar problemas 
de baixa qualidade da proteína e desequilíbrio em aminoácidos. Este produto, além de melhorar a palatabilidade das rações, auxiliou a manutenção do equilíbrio osmótico pelos camarões.

Kubitza et al.(1997) demonstraram que a betaína não é eficiente como palatabilizante em raçōes para largemouth bass (Micropterus salmoides), contendo $0 \%$ de farinha de peixe e $60 \%$ de farelo de soja. Estes resultados são comparáveis àqueles de Moreau \& Dabrowski (1996), que demonstraram que a utilização de betaína $(2 \%)$ como palatabilizante em raçōes de juvenis de esturjāo do lago (Acipenser fulvencens), tem efeito significativo tanto na sobrevivência como no ganho de peso da espécie apenas quando combinada com 3 ou $6 \%$ de farelo de krill ou concentrado protéico de peixe. 


\section{MATERIAL E MÉTODOS}

Os experimentos foram realizados nas dependências do Laboratório de Nutrição de Peixes do Setor de Piscicultura do Departamento de Produção Animal, da Escola Superior de Agricultura "Luiz de Queiroz", "campus" Luiz de Queiroz da Universidade de São Paulo, em Piracicaba, SP. O laboratório é equipado com 32 caixas de polipropileno com capacidade unitária de $1000 \mathrm{~L}$, abastecidas por um sistema fechado de recirculação de água, dotado de filtro biológico. O controle de temperatura é realizado por uma bomba trocadora de calor marca Colsol, modelo BC 100. O fluxo d'água permitia um mínimo de 6 trocas diárias de todo o volume das caixas. Cada caixa representava um bloco, com três parcelas, representadas por gaiolas de tela de policloreto de vinila átoxico de abertura de malha $5 \mathrm{~mm}$ e volume unitário de $60 \mathrm{~L}$ (dimensões de $52 X 27 X 44)$. O laboratório era iluminado por oito lâmpadas de halogênio, com $370 \mathrm{~W}$, controladas por temporizador, que proporcionava um fotoperíodo de 12 $x$ 12horas.

Os parâmetros oxigênio dissolvido e a temperatura da água do sistema foram monitorados diariamente (08:00 e 18:00), utilizando-se um oxímetro digital da marca Mettler Toledo modelo MO 128. Semanalmente eram monitorados s parâmetros de $\mathrm{pH}$, alcalinidade, dureza e os níveis de amônia não ionizada na água, com a utilização de um kit para aquicultura marca Hach, modelo FF-2.

Raçōes purificadas formuladas com albumina ou caseina são comumente utilizadas (a) na determinação de exigências nutricionais (Kim, et al., 1991); (b) na cinética, níveis de inclusão e de substituições de vitaminas, 
aminoácidos, ácidos graxos e minerais (Dabrowski et al.,1987; Hung et al., 1987; Masumoto et al.,1987; Celada et al., 1989; Gunther \& Meyer-Burgdorff, 1990; Sheen \& D'abramo, 1991; D'abramo \& Sheen, 1993; Taveekijakran et al., 1994; Paripatananont \& Lovell, 1995a; Vielma \& Lall, 1998); (c) em testes da eficiência desses nutrientes ou de antibióticos e quimioterápicos quando animais são submetidos a desafios microbianos ou ambientais (DePaola, 1995; Paripatananont \& Lovell, 1995b; Wang et al., 1997; Eya \& Lovell, 1998); ou finalmente, (d) para verificar a ação de corantes ou as taxas de consumo de alimentos ( Hung \& Lutes, 1987; Hardy et al., 1990; Torrissen et al., 1990) de peixes, crustáceos ou outros animais.

As raçōes purificadas utilizadas nos experimentos deste estudo, todas com a mesma composição básica e suplementação vitamínica e mineral completas (Tabela 1), foram confeccionadas no Laboratório de Nutrição Aquática da Faculdade de Medicina Veterinária e Zootecnia da Universidade Estadual Paulista, "campus" de Botucatu, SP. O procedimento para preparo das rações seguiu recomendações de Halver (1991) e NRC (1993), e pode ser resumido nos seguintes passos:

1. pesagem individual dos ingredientes, em balança digital com precisão de milésimos de grama;

2. adição das pré-misturas de vitaminas e minerais;

3. adição da vitamina $C$;

4. adição do cloreto de colina e/ou da betaína nas doses utilizadas em cada ração experimental;

5. misturadas manual dos ingredientes;

6. adição de água à mistura (150 à $200 \mathrm{ml} / \mathrm{kg}$ de ração);

7. granulação pela passagem da ração por moedor manual;

8. secagem em estufa com circulação de ar, por um período de $10-12$ horas, a uma temperatura de $52 \pm 2{ }^{\circ} \mathrm{C}$;

9. quebra dos grânulos secos em triturador manual; 
10. passagem dos grânulos quebrados por jogo de peneiras para separação dor grânulos desintegrados nas 3 classe de tamanho utilizadas no experimento: partículas menores que $1,00 \mathrm{~mm}$, partículas entre 1,00 mm e 2,36 mm; partículas entre 2,36 mm e 2,80 mm.

Tabela 1. Composição centesimal da ração purificada.

\begin{tabular}{lc}
\hline Ingredientes & $\%$ \\
\hline Albumina & 32,10 \\
Gelatina & 7,70 \\
Amido & 44,13 \\
Óleo de Soja & 6,00 \\
$\alpha$-Celulose & 6,00 \\
Fosfato bicálcico & 3,00 \\
Pré-mistura de vitaminas e minerais & 0,50 \\
Vitamina C & 0,05 \\
Cloreto de sódio & 0,50 \\
BHT & 0,02 \\
\hline Total & 100,00 \\
\hline \hline
\end{tabular}

Niveis de garantia da pré-mistura de vitaminas e minerais (Supremais) por $\mathrm{kg}$ de produto: vit. $A=1.200 .000$ UI; vit. $D 3=200.000 \mathrm{Ul}$; vit. $\mathrm{E} 12,000 \mathrm{mg}$; vit. $K 3=2.400 \mathrm{mg}$; vit. $B 1=4.800 \mathrm{mg}$; vit. $B 2=4.800 \mathrm{mg}$; vit. $B 6=4.000 \mathrm{mg}$; vit. $B 12=4.800 \mathrm{mg}$; ác. Fólico $=1.200 \mathrm{mg}$; pantotenato de cálcio $=1.200 \mathrm{mg}$; vit. $C=48.000 \mathrm{mg}$; biotina $=48 \mathrm{mg} ;$ niacina $=24.00 \mathrm{mg}$; ferro $=10.000 \mathrm{mg}$; cobre $=600 \mathrm{mg} ;$ manganês $=4.000 \mathrm{mg}$ zinco $=6.000 \mathrm{mg}$; iodo $=20 \mathrm{mg}$; cobalto $=2 \mathrm{mg} ;$ selênio $=20 \mathrm{mg}$.

Vit. C (Lutavit C-Aquastab); sal cálcica 2 - monofosfato de ácido ascórbico com $42 \%$ de princípio ativo.

$\mathrm{BHT}=$ Butil Hidroxi Tolueno

A composição bromatológica das rações experimentais foi determinada por análise no Laboratório de Bromatologia do Departamento de Produçào Animal da ESALQ/USP, Piracicaba, SP. Os resultados obtidos estão apresentados na Tabela 2. 
Tabela 2. Composição bromatológica das rações experimentais.

\begin{tabular}{lcc}
\hline Parâmetro & Ração B1E & Ração B2E \\
\hline & $(\%)$ & $(\%)$ \\
Matéria seca & 92,30 & 92,84 \\
Proteina Bruta & 33,67 & 34,67 \\
Extrato etéreo & 4,03 & 4,66 \\
Material mineral & 5,07 & 3,09 \\
Fibra bruta & 5,60 & 6,11 \\
\hline
\end{tabular}

Foram utilizados dois lotes monosexo de tilápias do Nilo, obtidos por processo de reversão sexual com utilização do hormônio metil-testosterona, conforme descrito por Popma \& Green (1990), adquiridos da Piscicultura da Chácara Santa Bárbara, Itupeva, SP. A taxa de reversão sexual dos lotes foi determinada pela técnica do aceto-carmin, conforme Guerrero \& Shelton (1974). A porcentagem de machos no lote destinado ao primeiro ensaio foi de $93 \%$, e no lote destinado ao segundo ensaio a porcentagem de machos foi de $97 \%$. Estes valores estão dentro dos padrões aceitáveis para taxa de reversão sexual (Popma \& Lovshin, 1996). Antes do início dos experimentos, os peixes passaram por um período de adaptação às instalações e rotina do laboratório de 3 dias.

\subsection{Experimento I}

Grupos de 10 tilápias do Nilo com peso médio de 5,09 $\pm 0,14 \mathrm{~g}$ foram estocados em 30 gaiolas e foram alimentados ad libitum, duas vezes ao dia, sete dias por semana, por seis semanas (42 dias), com seis dietas experimentais contendo $0,0 \mathrm{mg}$; $375 \mathrm{mg} ; 750 \mathrm{mg}$; $1125 \mathrm{mg} ; 1500 \mathrm{mg}$ ou $1875 \mathrm{mg}$ de cloreto de colina (na forma líquida, com $75 \%$ de cloreto de colina) por $\mathrm{kg}$ de alimento, em um delineamento experimental em blocos incompletos totalmente ao acaso, com 
3 parcelas em cada bloco, com 5 repetiçòes por tratamento (Cochran \& Cox, 1957; Steel \& Torrie, 1980).

Durante o período experimental foram realizadas quatro biometrias inicial, aos quinze dias, aos trinta dias e ao final do experimento quinzenais. Foi adotado o seguinte procedimento para a execução das biometrias: todos os exemplares de cada parcela eram capturados e anestesiados por imersão em solução de benzocaína, $(1 \mathrm{~g} / 10 \mathrm{~L}$ de água), lotes de 5 peixes eram selecionados ao acaso e pesados em balança eletrônica com capacidade para $500 \mathrm{~g}$ e precisão de centésimos de grama.

Ao final do período experimental, dois exemplares de cada parcela foram coletados ao acaso e triturados em liquidificador. O material coletado foi processado e armazenado para posterior análise conforme descrito a seguir. Os oito exemplares restantes foram sacrificados e laparotomizados para remoção do tecido hepático, que também foi armazenado para posterior análise.

O desempenho dos peixes dos diferentes tratamentos foi avaliado com base na variação do ganho de peso, sobrevivência, conversão alimentar, quantidade total de lipídeos no corpo e no fígado. As análises químicas foram conduzidas por procedimentos de rotina no Laboratório de Bromatologia do Departamento de Produção Animal da ESALQ/USP.

\subsection{Experimento II}

Para realização do Experimento $\Pi$, foram utilizadas duas super-doses de cloreto de colina $(1250 \mathrm{mg} / \mathrm{kg} ; 2500 \mathrm{mg} / \mathrm{kg})$, com a intenção de observar a ocorrência de acúmulo de lipídeos no fígado e no tecido corporal, observando-se que no experimento I, a suplementação acima de $375 \mathrm{mg}$ de cloreto de colina por $\mathrm{kg}$ de alimento mostrou-se suficiente para suprir as exigências nutricionais da tilápia em relação aos parâmetros de desempenho: ganho de peso e conversão alimentar. $O$ Experimento $\amalg$ teve por finalidade avaliar os efeitos da 
suplementação dietética de colina em doses mais elevadas e da substituição da colina por betaína (Betafin; $99 \%$ de betaína; Betec) nas dietas, sobre depósitos de gordura no fígado e na tecido corporal, conversão alimentar, ganho de peso e sobrevivência.

Uma vez mais, grupos de 10 tilápias do Nilo com peso médio de 2,14 \pm $0,07 \mathrm{~g}$ foram estocados em 30 gaiolas e foram alimentados ad libitum, duas vezes ao dia, sete dias por semana, durante 52 dias, com seis dietas experimentais contendo $1250 \mathrm{mg}$ ou $2500 \mathrm{mg}$ de cloreto de colina líquido por $\mathrm{kg}$ de alimento; $1000 \mathrm{mg}, 2000 \mathrm{mg}$ ou $3000 \mathrm{mg}$ de por $\mathrm{kg}$ de alimento, além da dieta controle, em um delineamento experimental em blocos incompletos totalmente ao acaso, com 5 repetições por tratamento. Os procedimentos adotados para a realização das biometrias, coleta e armazenagem do material biológico para análise, e parâmetros de desempenho e composição corporal e do fígado foram idênticos àqueles do Experimento $\mathrm{I}$.

\subsection{Procedimentos analíticos}

As amostras de tecido corporal e hepático foram congeladas por imersão em nitrogênio líquido e estocadas em super-congelador $\left(-25^{\circ} \mathrm{C}\right)$. As amostras de fígado foram acondicionadas em formas de alumínio e as amostras de tecido corporal foram acondicionadas em recipientes de papel alumínio e foram liofilizadas (Labenco, modelo Lyph Lock 6) por 12 horas. Em seguida, as amostras de fígado foram moídas manualmente em cadinho e acondicionadas em tubos de Ependorf $(1,5 \mathrm{ml})$. As amostras de tecido corporal foram moídas em moinho de facas tipo Wille (Thomas) e colocadas em tubos de Falcon (15 ml).

Para análise de extrato etéreo foi utilizada a metodologia de lavagem sucessiva da amostra com o solvente éter de petróleo, em aquecedor cibelin e conjunto extrator de Soxhlet. Para análise do tecido corporal, as amostras eram pesadas em balança analítica (Ohaus) com precisão de milésimo de grama; duas 
alíquotas de aproximadamente $1 \mathrm{~g}$ de cada amostra eram colocadas em papel filtro (Whatman) de $12,5 \mathrm{~cm}$ de diâmetro, dobrado de forma a não permitir a perda de material. Em seguida, o extrator era conectado ao balão, previamente seco em estufa a $100{ }^{\circ} \mathrm{C}$ (Fanem; Mod $315 \mathrm{SE}$ ) e tarado. Em seguida era adicionado éter de petróleo até que ocorresse por duas vezes a sinfonagem. A amostra era então destilada por 5-6 horas e após esse período, o envelope com a amostra era retirado, e a destilação continuava em branco, para que o éter ficasse retido na câmara do extrator. Os balōes eram então colocados em estufa (FabbePrimar Mod 219/3) a $80^{\circ} \mathrm{C}$, durante 3-4 horas. Os balōes eram resfriados em dessecador e depois pesados.

O extrato etéreo era então calculado por método direto, considerandose o extraído, da seguinte forma:

Extrato etéreo $=p^{\prime}-p$, sendo:

- $\mathrm{p}^{\prime}=$ peso do balão mais extraído

- $\mathrm{p}=$ tara do balão

- $\%$ extrato etéreo $=\left(p^{\prime}-p / \text { peso da amostra }\right)^{\star} 100$

A análise das amostras de fígado era feita pelo mesmo procedimento. Entretanto, em função da menor quantidade de material disponível, o papel de filtro utilizado possuía $9,5 \mathrm{~cm}$ de diâmetro. 


\section{RESULTADOS E DISCUSSÃO}

A variação dos parâmetros de qualidade da água, monitorados durante a execução dos dois experimentos, esteve dentro dos seguintes limites: temperatura $28,63 \pm 0,66^{\circ} \mathrm{C}$; oxigênio dissolvido $7,22 \pm 0,36 \mathrm{mg} / \mathrm{L} ; \mathrm{pH} 7,5 \pm 0,06$; alcalinidade 112,67 $\pm 8,9 \mathrm{mg} \mathrm{CaCO} / \mathrm{L}$; dureza 90,00 \pm 7,1 $\mathrm{mg} \mathrm{CaCO}_{3} / \mathrm{L}$; amônia total $0,16 \pm 0,08 \mathrm{mg} / \mathrm{L}$. Esses valores são adequados ao conforto ambiental da espécie em estudo e as variações observadas estão dentro dos intervalos recomendados para a criação de peixes (Boyd, 1996; Keenleyside , 1991).

Não foram observadas efeitos dos blocos e diferenças estatísticas entre os dados de desempenho e concentração corporal e hepática de lipídios obtidos no Experimento I (Tabela 3). Com exceção do tratamento com $1125 \mathrm{mg}$ de colina/ $\mathrm{kg}$ de alimento, onde a sobrevivência foi de $98 \%$, a taxa de sobrevivência dos demais tratamentos foi de $100 \%$. 
Tabela 3. Resultados de desempenho e concentração corporal e hepática de lipídios obtidos no Experimento I.

\begin{tabular}{lcccccc}
\hline $\begin{array}{c}\text { Suplementação } \\
\text { de colina/kg } \\
\text { de alimento }\end{array}$ & $\begin{array}{c}\text { Peso inicial } \\
\text { do lote }\end{array}$ & $\begin{array}{c}\text { Ganho } \\
\text { de peso }\end{array}$ & $\begin{array}{c}\text { Conversão } \\
\text { alimentar }\end{array}$ & $\begin{array}{c}\text { Concentração } \\
\text { de lipidios no } \\
\text { tecido corporal }\end{array}$ & $\begin{array}{c}\text { Concentração } \\
\text { de lipidios no } \\
\text { figado }\end{array}$ & Sobrevivência \\
\hline$(\mathrm{mg})$ & $(\mathrm{g})$ & $(0 \mathrm{~g})$ & $(\mathrm{g} / \mathrm{g})$ & $(\%)$ & $(\%)$ & $(\%)$ \\
0 & $50,99 \pm 1,24$ & 97,43 & 1,37 & 20,92 & 5,74 & 98 \\
375 & $50,18 \pm 0,23$ & 108,12 & 1,21 & 20,72 & 5,70 & 100 \\
750 & $52,09 \pm 2,52$ & 104,86 & 1,24 & 21,56 & 4,82 & 100 \\
1125 & $51,31 \pm 1,41$ & 106,63 & 1,29 & 20,94 & 6,84 & 100 \\
1500 & $50,04 \pm 0,38$ & 105,32 & 1,26 & 21,54 & 5,00 & 100 \\
1875 & $50,60 \pm 0,54$ & 105,11 & 1,22 & 21,21 & 6,16 & 100 \\
\hline
\end{tabular}

Foram observadas diferenças significativas para ganho de peso e conversão alimentar apenas entre o tratamento controle e os demais tratamentos, que não diferiram estatisticamente entre si. Pode-se inferir, portanto, que a suplementação de $375 \mathrm{mg}$ de cloreto de colina por $\mathrm{kg}$ de alimento é suficiente para atender as exigências nutricionais da tilápia para este nutriente.

A não ocorrência de diferenças significativas para concentração de lipídeos no fígado e corporal total da tilápia, diferem dos resultados obtidos por Craig \& Gatlin (1997), que alimentaram juvenis de red drum (Sciaenops ocellatus), com peso médio de 2,6 g com uma ração semipurificada contendo $3.000 \mathrm{mg}$ de colina/ $\mathrm{kg}$ de ração, seja na forma de cloreto de colina ou colina bitrato, e observaram um aumento na quantidade de lipídeos no músculo e diminuição da quantidade de lipídios no fígado. Entretanto, ao contrário dos resultados aqui observados, a suplementaçào com colina não teve efeito positivo sobre a conversão alimentar do "red drum".

Roem et al. (1990) não observaram diferenças significativas no ganho de peso, conversão alimentar, ou sobrevivência de tilápias áurea alimentadas com raçōes purificadas suplementadas com $0 ; 250 \mathrm{mg} ; 500 \mathrm{mg} ; 1.000 \mathrm{mg}$ ou 2.000 $\mathrm{mg}$ de colina por $\mathrm{kg}$ de ração. Estes autores observaram apenas um aumento no 
teor de lipídeos no fígado, de $4 \%$ no início para $8 \%$ no final do experimento, mas não conseguiram determinar as causas desta variaçào. Diferente dos resultados obtidos com tilápia nilótica, os autores consideram não ser necessária a suplementação com colina nas raçōes para tilápias áurea criadas em sistemas de recirculação de água, provavelmente em função do aproveitamento das bactérias presentes no sistema pela espécie.

Este estudo com tilápia nilótica foi também conduzido em sistema de recirculação de água que se manteve cristalina durante todo o período experimental. Desta forma, os resultados obtidos, tanto no Experimento I como no Experimento II demostram a necessidade de suplementação alimentar de colina, já que todos os tratamentos com inclusão de colina foram superiores ao tratamento controle no Experimento $I$, bem como os tratamentos com suplementação de colina foram superiores tanto aos tratamentos com suplementação de betaína como ao tratamento controle no Experimento II.

Trabalhando com salmões do Atlântico (Salmo salar) com pesos inicias de $0,18 \mathrm{~g} ; 1,0 \mathrm{~g} ; 1,7 \mathrm{~g}$ e $7,5 \mathrm{~g}$, alimentados com uma ração semipurificada suplementada com 0,3\% de colina, Poston (1990a) observou um aumento no teor de lipídeos corporais somente para peixes com peso inicial inferior a 1,7 gramas. Nos dois experimentos conduzidos neste estudo, o peso inicial dos peixes foi superior a 2,0 g, e esta pode ser uma das causas de não terem sido observadas diferenças significativas em função dos níveis de suplementação alimentar com colina. Diferente dos resultados obtidos nos dois ensaios feitos com tilápia, a suplementação alimentar com colina não afetou a conversão alimentar do salmão do Atlântico.

Trabalhando com larvas de truta arco-íris (Oncorhynchis mykiss) de peso inicial entre $0,10-0,12 \mathrm{~g}$, Poston (1990b) observou que as larvas alimentadas com rações semipurificadas suplementadas com $0,3 \%$ colina, apresentaram melhor crescimento em comparação às larvas não suplementadas. Estes resultados de desempenho são semelhantes àqueles obtidos neste estudo. Já em 
relação à taxa de sobrevivência, as larvas de truta alimentadas com raçôes suplementadas com colina tiveram um desempenho bastante superior ao controle, porém inferior às larvas que receberam uma ração com $72 \%$ de farinha de arenque. Entretanto, estes resultados de Poston (1990b) podem estar associados tanto ao maior teor de proteína como a uma maior quantidade e melhor balanço de aminoácidos na ração que continha farinha de peixe.

Rumsey (1991) alimentou trutas arco-íris com uma rações purificadas contendo (a) diferentes níveis de inclusão de colina (0; 200 ppm; 400 ppm; 600 ppm; 800 ppm ou 1.000 ppm), (b) um inibidor da síntese de colina, o 2-amino-2metil-1-propanol (AMP), incluído na dose de 0,3\%; (c) 0,3\% de AMP + 1.000 ppm de colina; ou (d) uma ração suplementada com $0,37 \%$ de metionina. A suplementação alimentar com colina se mostrou melhor que os tratamentos com inibidor ou com suplementação de metionina em relação à conversão alimentar; a adição do AMP não teve efeito quando foi utilizada a suplementação com colina. Embora o melhor resultado para ganho de peso tenha sido observado para um valor estimado de $813 \mathrm{ppm}$ de colina, todos os resultados não diferiram entre si quando o nível de suplementação foi superior a $200 \mathrm{ppm}$. Estes resultados são semelhante àqueles obtidos neste estudo com tilápia nilótica, em que a suplementação com $350 \mathrm{mg}$ de cloreto de colina atendeu as exigências nutricionais da tilápia.

Como já comentado, os valores de suplementação de colina recomendado pela literatura são superiores àqueles encontrados no experimento I. Deste modo, o Experimento II testou a utilização de super-suplementação com cloreto de colina e níveis de substituição de colina por betaína nas rações da tilápia do Nilo. Os resultados do Experimento II estão resumidos na Tabela 4 abaixo. 
Tabela 4. Resultados de desempenho e concentração corporal e hepática de lipídios obtidos no Experimento II.

\begin{tabular}{lcccccc}
\hline $\begin{array}{l}\text { Suplementação } \\
\text { kg de alimento }\end{array}$ & $\begin{array}{c}\text { Peso inicial } \\
\text { do lote }\end{array}$ & $\begin{array}{c}\text { Ganho } \\
\text { de peso }\end{array}$ & $\begin{array}{c}\text { Conversào } \\
\text { alimentar }\end{array}$ & $\begin{array}{c}\text { Concentração } \\
\text { de lipídios no } \\
\text { tecido corporal }\end{array}$ & $\begin{array}{c}\text { Concentração } \\
\text { de lipídios no } \\
\text { fígado }\end{array}$ & Sobrevivência \\
\hline$(\mathrm{mg})$ & $(\mathrm{g})$ & $(0 \mathrm{~g})$ & $(\mathrm{g} / \mathrm{g})$ & $(\%)$ & $(\%)$ & $(\%)$ \\
0 & $21,90 \pm 0,66$ & 87,22 & 1,37 & 27,90 & 10,66 & 98 \\
colina, 1250 & $21,49 \pm 0,66$ & 89,09 & 1,21 & 28,73 & 11,58 & 94 \\
colina, 2500 & $21,32 \pm 0,86$ & 93,03 & 1,24 & 28,93 & 9,70 & 100 \\
betaina, 1000 & $21,44 \pm 0,66$ & 81,96 & 1,29 & 27,17 & 8,45 & 96 \\
betaina, 2000 & $21,88 \pm 0,87$ & 87,72 & 1,26 & 27,26 & 12,01 & 94 \\
betaína, 3000 & $21,39 \pm 0,83$ & 12,51 & 1,22 & 28,68 & 13,92 & 94 \\
\hline \hline
\end{tabular}

Não foi observada influência dos blocos no desempenho dos peixes. Para análise e comparação dos resultados de conversão alimentar, ganho de peso, sobrevivência, concentração corporal e hepática de lipídios de extrato etéreo no fígado e no corpo total dos diferentes tratamentos, foram utilizados contrastes, assim definidos:

- $\quad \mathrm{Y} 1=$ tratamento controle vs. demais tratamentos;

- $\mathrm{Y} 2=$ doses de colina vs. doses de betaína;

- $\quad \mathrm{Y} 3=$ entre as doses de betaína;

- $\mathrm{Y} 4$ = efeito linear das doses de betaína;

- $Y 5$ = efeito quadrático das doses de betaína;

- $\mathrm{Y} 6=$ entre as doses de colina.

Não foram observadas diferenças significativas entre os tratamentos para nenhum dos contrastes testados no que se refere aos teores de lipídios corporais e hepáticos e sobrevivência. Para o contrate Y6 não foram detectadas diferenças significativas também para os parâmetros de ganho de peso e conversão alimentar.

No contraste $Y 1$ foi constatada diferença para ganho de peso e conversão alimentar. No contraste $\mathrm{Y} 2$, ocorreram diferenças significativas entre 
colina e betaína, tanto para ganho de peso como para conversão alimentar, demostrando também um efeito superior da colina sobre a betaína.

No contraste Y3 foram observadas diferenças entre as doses de betaína e correlacionando-se com os contrastes $\mathrm{Y} 4$ (efeito linear) e Y5 (efeito quadrático), a equação linear é a que melhor se adequa aos resultados obtidos. As equações que melhor demonstram o efeito negativo de doses maiores de betaína para 0 intervalo utilizado são as seguintes:

Conversão alimentar

Ganho de peso

$$
\begin{aligned}
& Y=-3,52+0,003844 X \\
& Y=130,18-0,034725 X
\end{aligned}
$$

Hughes (1993), utilizando diversos estimulantes para aumentar o consumo de ração, observou um menor consumo de alimento por larvas de salmão Chinook alimentadas com uma ração suplementada com $1,311 \%$ de betaína. $\mathrm{O}$ autor associou essa diminuiçào do consumo à forma da betaína adicionada, que foi a hidrocloreto.

Rumsey (1991) observou que larvas de truta alimentadas com ração suplementada com betaína apresentaram desempenho inferior àquelas truta alimentadas com ração suplementada com colina, em relação ao ganho de peso e conversão alimentar. $O$ autor observou ainda que embora a suplementação com betaína não eliminasse o efeito negativo da adição de AMP às rações, 0 desempenho dos peixes alimentados com rações suplementadas com betaína era superior àquele dos peixes receberam rações suplementadas com metionina.

Em todos os ensaios conduzidos por Rumsey (1991), não foram constatadas variações nos teores de lipídios hepáticos da truta. Estes resultados são semelhante àqueles obtidos neste estudo com a tilápia nilótica, em que também não foram observadas variações significativas na concentrações de lipídeos hepáticos ou corporais. Não só o desempenho dos peixes que receberam rações suplementadas com betaína foi inferior tanto para ganho de peso como 
conversão alimentar, como também o desempenho dos peixes alimentados com a ração suplementada com $3.000 \mathrm{mg}$ de betaína $/ \mathrm{kg}$ de ração, foi inferior ao desempenho dos peixes que receberam a ração controle.

Finalmente, é interessante notar que foi observado que os peixes alimentados com as raçōes suplementadas com betaína apresentaram um comportamento apático, demorando um tempo superior aos demais tratamentos para iniciar a captura do alimento. Este comportamento pode ser resultante de um efeito negativo da suplementação dietética com betaína tanto sobre a palatabilidade das raçôes como sobre as rotas metabólicas dos peixes. 


\section{CONCLUSÕES}

Os dados obtidos permitem concluir que as exigências nutricionais de colina para alevinos de tilápia do Nilo (Oreochromis niloticus) podem ser satisfeitas com a adição de $375 \mathrm{mg}$ de cloreto de colina por $\mathrm{kg}$ de alimento. Os resultados obtidos permitem concluir ainda que a suplementação com betaína não poderia substituir a suplementação com colina em raçōes para a tilápia do Nilo. 


\section{REFERÊNCIAS BIBLIOGRÁFICAS}

ABURTO, A.; VAZQUEZ, M.; DALE, N.M. Strategies for utilizing overprocessed soybean meal: I. Amino acid supplementation, choline content, and metabolizable energy. Journal of applied Poultry Research, v.7, n.2, p. 189-195, 1998.

BETANCOURT, R. Betafin $®$ Conceitos básicos e novas aplicações na nutrição de suínos. 1999.

BOYD, C.E. Water Quality in Ponds for Aquaculture. Songkhala: Shrimp Mart, 1996. $482 \mathrm{p}$.

CASTAGNOLLI, N. Criação de peixes de água doce. Jaboticabal: FUNEP, 1992. 189p.

CELADA, J.D.; CARRAL, J.M.; GAUDIOSO, V.R.; TEMINO, C.; FERNÁNDEZ, R. Responses of Juvenile Freshwater Crayfish (Pacifastacus leniusculus Dana) to Several Fresh and Artificially Compounded Diets. Aquaculture, v. 76, n. 12, p. 67-78, 1989.

COMBS, G.F.Jr The Vitamins - Fundamental aspects in nutrition and health San Diego: Academic Press, 1992. 526 p.

COCHRAN, W.G.; COX,G.M. Experimental Designs. 2.ed. New York: John Wiley \& Sons, 1957. 614 p.

CRAIG, S.R.; GATLIN, D.M.III Dietary Choline Requirement of Juvenile Red Drum (Sciaenops ocellatus). The Journal of Nutrition, v. 126, n. 6, p. 16961700, 1996.

CRAIG, S.R.; GATLIN, D.M.III Growth and body composition of Juvenile Red Drum (Sciaenops ocellatus) fed diets containing lecithining and supplemental choline. Aquaculture, v. 151, n. 1-4, p. 259-267, 1997. 
D'ABRAMO, L. R.; SHEEN, S.S. Polyunsatured fatty acid nutrition in juvenile freshwater prawn Macrobrachium rosenbergii. Aquaculture, v. 115, n. 1-2, p. 63-86, 1993.

DABROWSKI, K.;KAUSHIK, S.J.; FAUCONNEAU, B. Rearing of Sturgeon (Acipenser baeri Brandt) Larvae. III- Nitrogen and energy Metabolism and Amino Acid Absorption. Aquaculture, v. 65, n. 1, p. 31-41, 1987.

DePAOLA, A. Tetracycline Resistance by Bacteria in Response to Oxytetracycline-Contaminated Catfish Feed. Journal of Aquatic Animal Health, v. 7, n. 2 , p. 155-160, 1995.

EMMERT, J.L.; BAKER, D.H. A Chick Bioassay for Determining the Bioavailable Choline Concentration in Normal and Overheated Soybean Meal, Canola Meal and Peanut Meal. Journal of Nutrition, v. 127, n.5, p. 745-752, 1997.

EYA, J.C.; LOVELL, R.T. Effects of Dietary Phosphorus on Resistance of Channel Catfish to Edwardisella ictaluri Challenge Journal of Aquatic Animal Health, v. 10, n. 1, p. 28-34, 1998.

FAO. Fishery Statistics: catches and landings. Roma 1994 (FAO Fisheries Series N. 44.)

GUERRERO, R.D. ; SHELTON, W.L. An aceto-carmine squash method for sexing juvenile fishes. The Progressive Fish Culturist, v. 36, n. 1, p. 56, 1974.

GRIFFIN, M.E.; WIISON, K.A.; WHITE, M.R.; BROWN, P.B. Dietary Choline Requirement of Juvenile Hybrid Striped Bass. The Journal of Nutrition, v. 124, n. 9, p. 1685-1689, 1994.

GUNTHER, K.D.; MEYER-BURGDORF, K.H. Studies on Biotin Supply to Mirror Carp (Cyprinus carpio L.). Aquaculture, v. 84, n. 1, p. 49-60, 1990.

HALVER, J.E. The Vitamins. In: HALVER, J.E. (Ed.) Fish Nutrition. San Diego: Academic Press, Inc. 1991. p.32-111.

HARDY, R.W.; TORRISSEN,O. J.; SCOTT, T.M. Absorption and Distribution of 14 C-Labeled Canthaxanthin in Rainbow Trout (Oncorhynchus mykiss). Aquaculture, v. 87, n. 3-4, p. 331-340, 1990.

HUGHES; S.G. Single-Feeding Response of Chinook Salmon Fry to Potential Feed Intake Modifiers. The Progressive Fish Culturist, v. 55, n. 1, p. 40-42, 1993. 
HUNG, S.S.O.; MOORE, B.J.;BORDNER, C.E.; CONTE, F.S. Growth of Juvenile White Sturgeon (Acipenser transmontanus) Fed Different Purified Diets. Journal of Nutrition, v. 117, n. 2, p. 328-334, 1987.

HUNG, S.S.O.; LUTES,P.B. Optimum Feeding Rate of Hatchery-Produced Juvenile White Sturgeon (Acipenser transmontanus): at $20^{\circ} \mathrm{C}$. Aquaculture, v. 65, n. 3-4, p. 307-317, 1987.

KEENLEYSIDE, M.H.A. Cichlid Fishes: Behaviour, ecology and evolution. London: Chapman \& Hall, 1990. 378 p. (Fish and Fisheries Series 2)

KIM, K.IL; KAYES, T.B.; AMUNDSON, C.H. Purifeid diet development and reevaluation of the dietary protein requirement of fingerling rainbow trout (Oncorhinchus mykiss). Aquaculture, v. 65, n. 1, p. 31-41, 1991.

KUBITZA, F.; LOVSHIN, L.L.; LOVELL, R.T. Identification of feed enhancers for juvenile largemouth bass Micropterus salmoides. Aquaculture, v. 148, n. 23, p. 191-200, 1997.

LUND, V.C.F.X. ; FIGUEIRA, M. de L. O. A. Criação de tilápias. São Paulo: Nobel, $1989.63 \mathrm{p}$.

MARTIN, N. B.; SCORVO FILHO, J. D.; SANCHES, E. G.; NOVATO, P. F. C.; AYROSA, L. M. S. Custos e retornos da piscicultura em São Paulo. Informações Econômicas, v. 25, n. 1, p. 9-47, 1995.

MARTINEZ, M.; PEDINI, M. Global Overview of Production and Production Trends. Latin America and the Caribbean <www.fao.org> (05/04/2000)

MATTHEWS, J.O.; SOUTHERN, L.L.; PONTIF, J.E.; HIGBIE, A.D.; BIDNER, T.D. Interactive effects of betaine, crude protein and net energy in finishing pigs. Journal of Animal Science, v. 76, n. 9, p. 2444-2455, 1998.

MASUMOTO, T.; HARDY, R.W. CASILLAS, E. Comparison of Transketolase Activity and Thiamin Pyrophosphate Levels in Erythrocytes and Liver of Rainbow trout (Salmo gairdneri) as Indicator of Thiamin Status. Journal of Nutrition, v. 117, n. 8, p. 1422-1426, 1987.

MCDOWELL, L.R. Vitamins in Animal Nutrition - Comparative Aspects to Human Nutrition. San Diego: Academic Press, 1989. 486 p.

MENTEN, J.F.M.; PESTI, G.M.; BAKALLI, R.I. A New Method for Determining the Availability of Choline in Soybean Meal. Poultry Science, v. 76, n. 9, p. 1292-1297, 1997. 
MOREAU, R.; DABROWSKI, K. Feeding stimulants in semipurified diets for juvenile lake sturgeon, Acipenser fulvescens Rafinesque. Aquaculture Research, v. 27, n. 12, p. 953-957, 1996.

NATIONAL RESEARCH COUNCIL Nutrient Requeriments of Fish. Washington D.C.: National Academy Press, 1993. 114p.

PARIPATANANONT, T.; LOVELL, R.T. Chelated zinc reduces de dietary zinc requirement of channel catfish, Ictalurus punctatus. Aquaculture, v. 133, n. 1, p. 73-92, 1995a.

PARIPATANANONT, T.; LOVELL, R.T. Responses of Channel Catfish Fed Organic and Inorganic Sources of Zinc to Edwardisella ictaluri Challenge. Journal of Aquatic Animal Health, v. 7, n. 2 , p. 147-154, 1995b.

PENĀFLORIDA, V.dy; VIRTANEN, E. Growth, survival and feed conversion of juvenile shrimp (Penaeus monodon) fed a betaine/amino acid additive. The Israeli Journal of Aquaculture, v. 48, n. 1, p. 3-9, 1996.

POPMA, T.J.; GREEN, B.W. Sex Reversal of Tilapia in Earthen Ponds. International Center of Aquaculture. Alabama Agricultural Experiment Station, Auburn University. Research and Development Series no. 35, 1990. $15 \mathrm{p}$.

POPMA, T.J.; LOVSHIN, L.L. Worldwide Prospects for Commercial Production of Tilapia. International Center of Aquaculture. Alabama Agricultural Experiment Station, Auburn University. Research and Development Series no. 41, 1996. 23p.

POSTON, H. A. Effect of Body Size on Growth, Survival and Chemical Composition of Atlantic Salmon Fed Soy Lecithin and Choline. The Progressive Fish Culturist, v. 52, n. 4, p. 226-230, 1990a.

POSTON, H. A. Performance of Rainbow Trout Fry Fed Supplemental Soy Lecithin and Choline. The Progressive Fish Culturist, v. 52, n. 4, p. 218-225, 1990b.

RAMIREZ, M.C.; CROMWELL, G. Adicion de aminoacidos, vitaminas y minerales a dietas de sorgo-pasta de soya bajas en proteina, para cerdos en crecimiento. Agrociencia, v. 21, n. 2, p. 143-148, 1997

RANA, K.J. Aquatic Environments and Use of Species Groups. Reported use of culture environments for aquaculture production <www.fao.org> $(05 / 04 / 2000)$ 
ROEM,A.J.; STICKNEY, R.R.; KOHLER, C.C. Vitamin requirements of blue tilapia in recirculating water system. The Progressive Fish Culturist, v. 52, n. 1, p. 15-18, 1990.

RUMSEY, G.L. Choline-betaine requirements of rainbow trout (Oncorhynchus mykiss). Aquaculture, v. 95, n. 1-2, p. 107-116, 1991.

RYU, K.S.; ROBERSON, K.D.; PETI, G.M. The Folic Acid Requirements of Broiler Chicks Fed Diets Based on Practical Ingredients. 1- Interrelationships with Dietary Choline. Poultry-science, v. 74, n. 9, p. 1447-1455, 1997

SCHUTTE, J.B.; JONG, J. de; SMINK, W.; PACK, M. Replacement Value of Betaine for DL-Methionine in Male Broiler Chicks. Poultry-science, v. 76, $\mathrm{n}$. 2, p. 321-325, 1997

SCORVO FILHO, J. D. ; AYROSA, L. M. S. São Paulo: A situação da piscicultura no Estado. Panorama da Aquicultura, v. 6, n. 35, p.18 - 19, 1996.

SCORVO FILHO, J. D.; MARTIN,N. B. ; AYROSA, L. M. S. Piscicultura em São Paulo: custos e retornos de diferentes sistemas de produção na safra 1996/97. Informações Econômicas, v. 28, n. 3, p. 41-60, 1998.

SHEEN,S.S.; D'ABRAMO, L.R. Response of juvenile freshwater praw, Macrobrachium rosenbergii, to different levels of a cod liver oil/corn oil mixture in a semi-purified diet. Aquaculture, v. 93, n. 2, p. 121-134, 1991.

STEEL, R.G.D.; TORRIE, J.H. Principles and Procedures of Statistics: A biometrical approach. New York: McGraw-Hill Book Co., 1980. 633p.

SUGIURA, S.H.; DONG, F.M.; HARDY, R.W. Effects of dietary supplements on the availability of mineral in fish meal; preliminary observations. Aquaculture, v. 160, n. 3-4, p. 283-303, 1998.

TACON, A.G.J Contribution to Food Fish Supplies. Food fish supplies $<$ www.fao.org $>(05 / 04 / 2000)$

TAVEEKTIAKRAN, P.; MIYAZAKI, T.; MATSUMOTO, M.; ARAI, S. Vitamin A Deficiency in Cherry Salmon. Journal of Aquatic Animal Health, v. 6, n. 3, p. 251-259, 1994.

TESHIMA, S.; KANAZAWA, A.; KOSHIO, S. Recent Development in Nutrition and Microparticulate Diets of Laval Prawns. The Israeli Journal of Aquaculture, v. 45, n. 4, p. 175-184, 1993. 
TORRISSEN, O.J.; HARDY, R.W., SHEARER, K.D., SCOTT, T.M.; STONE, F.E. Effects of dietary canthaxanthin level and lipid level on apparent digestibility coefficients for canthaxanthin in rainbow trout (Oncorhynchus mykiss). Aquaculture, v. 88, n. 3-4, p. 351-362, 1990.

TSIAGBE, V.K.; HARPER, A.E.; SUNDE, M.L. A Feather-Sexed Strain of Laying Hens was More Responsive to Dietary Supplements of Choline and Methionine than a Vent-Sexed Strain. Poultry-science, v. 71, n. 8, p. 12711276, 1992.

VIELMA, J.; SANTOSH, P.L. Phosphorus utilization by Atlantic Salmon (Salmo salar) reared in freshwater is not influenced by higher dietary calcium intake. Aquaculture, v. 160, n. 1-2, p. 117-128, 1998.

WANG, C.; LOVELL, R.T; KLESIUS, P.H.. Response to Edwardisella ictaluri Challenge by Channel Catfish Fed Organic or Inorganic Sources of Selenium. Journal of Aquatic Animal Health, v. 9, n. 3 , p. 172-179, 1997.

WILSON, R. P. Fish and feed formulation and processing. In: SIMPÓSIO INTERNACIONAL SOBRE NUTRIÇÃO DE PEIXES E CRUSTÁCEOS, Campos do Jordão, 1995. Anais. Campinas : CBNA, 1995. P.53-68.

WOODWARD, B. Dietary vitamin requirements of cultured young fish, with emphasis on quantitative estimates for salmonids. Aquaculture, v. 124,n. 1, p. 133-168, 1994. 